\title{
Acute Neuroinflammation Impairs Context Discrimination Memory and Disrupts Pattern Separation Processes in Hippocampus
}

\author{
Jennifer Czerniawski and John F. Guzowski \\ Center for the Neurobiology of Learning and Memory, Department of Neurobiology and Behavior, University of California, Irvine, Irvine, California 92697-3800
}

\begin{abstract}
Although it is known that immune system activation can impair cognition, no study to date has linked cognitive deficits during acute neuroinflammation to dysregulation of task-relevant neuronal ensemble activity. Here, we assessed both neural circuit activity and context discrimination memory retrieval, in a within-subjects design, of male rats given systemic administration of saline or lipopolysaccharide (LPS). Rats were exposed over several days to two similar contexts: one of which was paired with weak foot shock and the other was not. After reaching criteria for discriminative freezing, rats were given systemic LPS or saline injection and tested for retrieval of context discrimination $6 \mathrm{~h}$ later. Importantly, LPS administration produced an acute neuroinflammatory response in dorsal hippocampus at this time (as assessed by elevation of proinflammatory cytokine mRNA levels) and abolished retrieval of the previously acquired discrimination. The impact of neuroinflammation on hippocampal CA3 and CA1 neural circuit activity was assessed using the Arc/ Homer la cellular analysis of temporal activity by fluorescence in situ hybridization imaging method. Whereas the saline-treated subjects discriminated and had low overlap of hippocampal ensembles activated in the two contexts, LPS-treated subjects did not discriminate and had greater ensemble overlap (i.e., reduced orthogonalization). Additionally, retrieval of standard contextual fear conditioning, which does not require context discrimination, was not affected by pretesting LPS administration. Together, the behavioral and circuit analyses data provide compelling evidence that LPS administration impairs context discrimination memory by disrupting cellular pattern separation processes within the hippocampus, thus linking acute neuroinflammation to disruption of specific neural circuit functions and cognitive impairment.
\end{abstract}

Key words: computation; discrimination; hippocampus; imaging; memory; neuroinflammation

\section{Introduction}

During neuroinflammation, elevated brain cytokine levels can mediate sickness behaviors and alter cognitive processes (Dantzer et al., 2008). Memory impairments and increased cytokine expression are observed in humans with such disorders as multiple sclerosis, Alzheimer's disease, and cancer (Huijbregts et al., 2004; Meyers et al., 2005; Guerreiro et al., 2007). To abrogate cognitive deficits associated with neuroinflammation, we need to understand how cytokines affect brain function at behavioral, cellular, and neural circuit levels.

At the behavioral level, systemic administration of the bacterial endotoxin lipopolysaccharide (LPS) increases brain expres-

Received Feb. 7, 2014; revised July 31, 2014; accepted Aug. 5, 2014.

Author contributions: J.C. and J.F.G. designed research; J.C. performed research; J.C. and J.F.G. analyzed data; J.C. and J.F.G. wrote the paper.

This work was supported by National Institutes of Health (NIH) Grant R01 MH08930 (J.F.G.), with additional support from NIH Training in the Neurobiology of Aging Grant AG00096 (J.C.). We thank Aaron Schiffman, Ellen Wann, and Aleksandr Pevzner for their assistance with data generation and analysis. We also thank, Teiko Miyashita and Aleksandr Pevzner for helpful discussions, and Craig Stark for his critical comments on a previous version of this manuscript.

The authors declare no competing financial interests.

Correspondence should be addressed to John F. Guzowski, 108 Bonney Research Laboratories, Irvine, CA 92697 3800. E-mail: john.g@uci.edu.

DOI:10.1523/JNEUROSCI.0542-14.2014

Copyright $\odot 2014$ the authors $\quad 0270-6474 / 14 / 3412470-11 \$ 15.00 / 0$ sion of proinflammatory cytokines interleukin- $1 \beta$ (IL- $1 \beta)$, interleukin-6 (IL-6), and tumor necrosis factor- $\alpha$ (TNF- $\alpha$ ) (Layé et al., 1994) and disrupts hippocampus-dependent memory tasks, including contextual, but not cued, fear conditioning and the spatial version of the Morris water maze (Pugh et al., 1998; Shaw et al., 2001). At the cellular level, long-term potentiation (LTP), AMPA receptor trafficking, and glutamate release can all be affected by the actions of proinflammatory cytokines (O'Connor and Coogan, 1999; Albensi and Mattson, 2000; D'Arcangelo et al., 2000; Beattie et al., 2002). Data from these in vitro studies demonstrate that cytokines can affect cell signaling pathways and synaptic plasticity and thus may be responsible for cognitive dysfunction after immune system activation in vivo.

Despite strong support for immune modulation of behavioral and cellular function, remarkably little is known about what effect elevated brain cytokine expression might have on neural circuit activity. Cognitive processes arise from the activity and interactions of distinct neural circuits. Therefore, to understand how and why neuroinflammation impairs cognition, it is important to know whether and how cytokines alter neural circuit activity. We examined the effect of acute neuroinflammation on context discrimination memory and neural circuit activity in the hippocampus. Context discrimination is strongly dependent on the hippocampus (Frankland et al., 1998) and is thought to be 
facilitated by pattern separation, a neural computation in which two similar input patterns are made more orthogonal (dissimilar) as output patterns (Guzowski et al., 2004; McHugh et al., 2007). At a neural level, the strongest pattern separation is thought to be accomplished through the use of two distinct (nonoverlapping) neuronal ensembles to encode the two experiences.

We tested the hypothesis that acute neuroinflammation impairs cognition by disrupting neuronal circuit activity using a context discrimination conditioning paradigm, in which rats acquire a discriminative fear response between two similar environments. After reaching the predetermined discrimination criterion, LPS or sterile saline (SAL) was administered systemically before a retrieval test. After testing, brain sections were analyzed by Arc/Homerla (H1a) cellular analysis of temporal activity by fluorescence in situ hybridization (catFISH), an immediate-early gene (IEG) imaging method used to compare hippocampal neuronal ensemble responses to two experiences (Vazdarjanova and Guzowski, 2004). The utility of Arc/H1a catFISH is attributable to the fact that transcriptional activation of the IEGs Arc and $\mathrm{Hla}$ occurs in neuronal ensembles in a context-specific manner. This integrative approach using a within-subjects design enabled us to link cognitive deficits at the behavioral level with alterations in the neural circuit activity level during acute neuroinflammation.

\section{Materials and Methods}

Subjects. Seventy-nine male Sprague Dawley rats (Charles River Laboratories) weighing $250-275 \mathrm{~g}$ at the time of arrival served as subjects. All animals were individually housed in a temperature-controlled vivarium maintained on a $12 \mathrm{~h}$ light/dark cycle (lights on at 6:00 A.M.). All subjects had access to food and water ad libitum throughout the duration of the experiment and were handled $2 \mathrm{~min} / \mathrm{d}$ for $5 \mathrm{~d}$ before the start of the experiment. On each day before training, all animals were transported to a holding room and allowed to sit undisturbed for $2 \mathrm{~h}$. All procedures complied with National Institutes of Health guidelines and were approved by the Institutional Animal Care and Use Committee of the University of California, Irvine.

Systemic drug administration and dosage. In the present study, rats were injected with either SAL (0.9\%) or LPS (167 $\mu \mathrm{g} / \mathrm{kg}$, i.p.; 100,000 EU/mg; lot \#028K4090; Sigma). This dose of LPS was chosen because it is within the range of doses $(100-250 \mu \mathrm{g} / \mathrm{kg})$ used previously in other studies examining the effect of LPS on learning and has been shown to inhibit LTP but not affect exploratory behavior (Pugh et al., 1998; Shaw et al., 2001, 2005; Hennigan et al., 2007; Bassi et al., 2012). Injections for all subjects were given from 8:00 A.M. to 11:30 A.M.

Quantitative real-time PCR. To determine peak levels of cytokine expression (IL-1 $\beta$, IL-6, and TNF- $\alpha$ ) in dorsal hippocampus, subjects were injected with SAL $(0.9 \%)$ or LPS (167 $\mu \mathrm{g} / \mathrm{kg}$, i.p., Sigma) and killed 3, 6, or $9 \mathrm{~h}$ later ( $n=3$ per group). Separate subjects serving as home-cage control subjects were removed from their home cage and killed without receiving any injections $(n=4)$. For all subjects, the brain was removed after rapid decapitation and flash frozen in isopentane. The brains were then stored at $-80^{\circ} \mathrm{C}$ until processed.

Total RNA was isolated using chloroform/isopropanol extraction from tissue punches of dorsal hippocampus. RNA was purified using the RNeasy Mini kit (Qiagen), and RNA purity was assessed using the ratio of absorbance at 260/280 and 260/230 nm (Pearl; Implen). Total RNA (1 $\mu \mathrm{g}$ ) was reverse transcribed using the $\mathrm{RT}^{2}$ First Strand cDNA Synthesis kit (SABiosciences). Quantitative real-time PCR was performed in an Eppendorf Mastercycler using the SYBR Green Master Mix (SABiosciences). The primers used were rat $\beta$-actin, IL- $1 \beta$, IL-6, and TNF- $\alpha$ (SABiosciences). Each sample was run in duplicate per gene of interest.

Relative quantification of mRNA was determined using the $\Delta \Delta \mathrm{C}_{\mathrm{T}}$ method (Livak and Schmittgen, 2001). Briefly, the duplicate values of threshold cycle $\left(\mathrm{C}_{\mathrm{T}}\right.$, cycle at which sample reached the threshold fluorescence level) for each sample were averaged. Mean $\mathrm{C}_{\mathrm{T}}$ values for actin, the endogenous control, were subtracted from the mean $C_{T}$ values of the gene of interest for each subject and served as the $\Delta \mathrm{C}_{\mathrm{T}}$. The mean $\Delta \mathrm{C}_{\mathrm{T}}$ from the home-cage control group served as the calibrator and was subtracted from the $\Delta \mathrm{C}_{\mathrm{T}}$ of the remaining subjects $\left(\Delta \Delta \mathrm{C}_{\mathrm{T}}\right)$. The fold change in the expression of the gene of interest, normalized to the endogenous control (actin), was then determined using the formula $2^{-\Delta \Delta} \mathrm{C}_{\mathrm{T}}$. The fold change values were then averaged for each of the respective groups.

Apparatus. Two similar but distinct chambers, each housed within a sound-attenuating chamber in the same room, were used for context discrimination conditioning. These chambers were the same size $(30.5 \times$ $25.4 \times 30.5 \mathrm{~cm})$ and cleaned with the same cleaning solution $(10 \%$ ethanol). The two key differences were as follows: (1) context A had a grid floor, whereas context A' had a flat surface; and (2) context A' had a pair of opposing walls in the shape of a slight " $\mathrm{A}$ " frame, whereas context A had only one wall at an angle for an asymmetric configuration. The floor of context A consists of 18 steel rods wired to a shock generator (Coulbourn Instruments) for delivery of footshock. Both chambers were constantly lit. Only context A was used for the single session of standard context fear conditioning.

Context discrimination conditioning. The contextual discrimination conditioning paradigm used was based on one that results in conditioned freezing to a specific context paired with shock (Fanselow and Helmstetter, 1988). Each subject was carried from its home cage into an adjacent room and placed into two similar behavioral chambers (A and $\mathrm{A}^{\prime}$ ) daily for $3 \mathrm{~min}$ each. The order of context presentation was pseudorandom and separated by $22 \mathrm{~min}$ (i.e., the second presentation occurred $25 \mathrm{~min}$ after the start of the first presentation). A single brief and weak footshock $(0.5 \mathrm{~mA}, 1 \mathrm{~s})$ was presented daily after $3 \mathrm{~min}$ in context A but not context $\mathrm{A}^{\prime}$. Subjects were removed from the chamber $20 \mathrm{~s}$ after the footshock presentation. Contextual fear was assessed by freezing, defined as a rigid posture and lack of movement except for that requiring respiration. Subjects were trained to criterion, defined by $\geq 25 \%$ freezing in context $A$ and $\leq 10 \%$ context $\mathrm{A}^{\prime}$ for 2 consecutive days with the order of context presentation counterbalanced. One day after reaching criteria, which took 6-9 d, the bacterial endotoxin LPS (167 $\mu \mathrm{g} / \mathrm{kg}$, i.p.; $n=9)$ or SAL $(n=8)$ was administered, and subjects were tested 6 h later. Testing consisted of $3 \mathrm{~min} 20 \mathrm{~s}$ in context $\mathrm{A}^{\prime}$ followed $22 \mathrm{~min}$ later by $5 \mathrm{~min}$ in context $\mathrm{A}$, and the animals were killed immediately after testing (see Fig. 3). No shock was presented in context A during testing to ensure that any findings from cell activity data were attributable to the context and not the shock presentation itself. Subjects were exposed to context A for 5 min instead of 3 min during testing to ensure maximal activation of $\operatorname{Arc}$ (Guzowski et al., 1999; Pevzner et al., 2012). A separate group of rats $(n=$ 4) received a single exposure (SE) to contexts $A^{\prime}$ and $A$, in the same manner as during the testing session described above, and were immediately killed. This was done to assess the initial overlap of activated neuronal ensembles in the hippocampus for the two similar contexts before repeated exposure and behavioral training to the contexts. An additional four subjects were killed directly from their home cage to establish baseline levels of IEG expression.

Because LPS can induce sickness behaviors, including lethargy (Dantzer et al., 2008), which could confound interpretations of freezing behavior, we ran additional subjects that were exposed to contexts A and $\mathrm{A}^{\prime}$ daily but never shocked. These subjects were then injected with SAL $(n=3)$ or LPS $(n=4)$ and tested the same day as their cohorts who had been trained in context discrimination conditioning.

Context fear conditioning. Separate subjects were trained in one training session of context fear conditioning and tested $24 \mathrm{~h}$ later. Subjects were placed into context $\mathrm{A}$ (the same conditioning chamber used in context discrimination conditioning) for $6 \mathrm{~min}$, with 3 footshocks (1 $\mathrm{mA}, 2 \mathrm{~s}$ ) presented after the first $3 \mathrm{~min}$, with a $1 \mathrm{~min}$ interval between each shock presentation. Subjects were injected with SAL $(n=9)$ or LPS $(n=11), 6 \mathrm{~h}$ before testing the following day, which consisted of being placed into context A for a 5 min testing session with no shock presentation. Freezing was observed by an experimenter blind to the subjects' condition.

Tissue processing. Immediately after testing, rats were placed in a sealed container containing isoflurane (to produce unconsciousness within $15 \mathrm{~s}$ ) and then decapitated. Brains were rapidly removed, flash frozen in an isopentane chamber immersed in a dry ice/ethanol bath (approxi- 
mately $-50^{\circ} \mathrm{C}$ ), and stored at $-80^{\circ} \mathrm{C}$. The frozen brains were then cryosectioned into 20- $\mu \mathrm{m}$-thick sections using a cryostat and mounted onto slides, with all experimental groups represented on each slide to help control for slide-to-slide variation.

Arc/H1a catFISH. Arc/Hla catFISH was used to visualize and compare neural circuit activity in CA3 and CA1 during testing. This imaging method exploits the precise temporal dynamics of transcription and processing of specific IEGs to allow researchers to infer the activity history of single neurons for two discrete behavioral epochs. Transcriptional activation of $A r c$ and $H 1 a$ is coincident in single neurons in the CA3 and CA1 subfields of the hippocampus (Vazdarjanova et al., 2002). However, because these primary transcripts have different lengths, $\mathrm{Hla}$ and Arc can be used as markers for neuronal activity during different behavioral epochs (exposure to contexts $\mathrm{A}^{\prime}$ and A) in CA3 and CA1. Nuclei with H1a-expressing $\left(\mathrm{HIa}^{+}\right)$transcription foci indicate neurons active $\sim 30$ min before the animal's death (context $\mathrm{A}^{\prime}$ ), whereas nuclei with $\mathrm{Arc}^{+}$ transcription foci indicate neurons active within $\sim 5 \mathrm{~min}$ of the animal's death (context A; Vazdarjanova et al., 2002). Thus, nuclei containing both $\mathrm{Arc}^{+}$and $\mathrm{H1a}^{+}$foci were active during both behavioral epochs (A and $\mathrm{A}^{\prime}$ ).

Although the dentate gyrus (DG), CA3, and CA1 are all thought to be involved in pattern separation (McNaughton and Morris, 1987; Guzowski et al., 2004; Leutgeb et al., 2007; McHugh et al., 2007), we were unable to use Arc/Hla catFISH to assess ensemble activity in DG during testing in the present study for several reasons. First, there is prolonged transcription of Arc in granule cells in the DG (Ramirez-Amaya et al., 2013) that prevents us from differentiating which cells were activated during the different behavioral epochs. Although it is possible to use an alternative IEG imaging approach more appropriate for the DG (Satvat et al., 2011), there are still important technical issues. For instance, electrophysiological data indicate that granule cells have sparse firing rates and that they can fire in multiple environments (Jung and McNaughton, 1993; Skaggs et al., 1996; Leutgeb et al., 2007; Alme et al., 2010). Importantly, very few granule cells $(\sim 2 \%)$ are active during exploration to different environments (Chawla et al., 2005; Ramirez-Amaya et al., 2006, 2013). Therefore, because of sampling issues and the sparsity of firing, it is difficult to get conclusive data on neuronal ensemble activity in DG and is thus commonplace to examine its downstream target, CA3 (McHugh et al., 2007; Niibori et al., 2012). Accordingly, in the present study, we used catFISH in CA3 to assess DG-CA3 circuit activity. Because CA3 and CA1 can have different neuronal ensemble dynamics (Vazdarjanova and Guzowski, 2004), we also looked at CA1 to determine whether any alterations in circuit activity in CA3 would be observed in its downstream target $\mathrm{CA} 1$, which is the main output of the hippocampus.

FISH. FISH procedures used here were described in detail previously (Guzowski et al., 1999; Vazdarjanova and Guzowski, 2004). Briefly, Arc and $\mathrm{Hla}$ hapten-labeled antisense riboprobes were hybridized together with the tissue overnight. Then, the digoxigenin-labeled Arc riboprobe was detected with anti-digoxigenin-HRP conjugate (Roche) and revealed with a cyanine- 3 tyramide signal amplification reagent (PerkinElmer Life and Analytical Sciences). After quenching with $2 \% \mathrm{H}_{2} \mathrm{O}_{2}$ to eliminate any residual HRP activity, the fluorescein-labeled probe targeting the $3^{\prime}$-UTR of $\mathrm{Hla}$ was detected with anti-fluorescein-HRP conjugate (Roche) and revealed with an FITC tyramide signal amplification kit (PerkinElmer Life and Analytical Sciences). Nuclei were counterstained with $4^{\prime}, 6^{\prime}$-diamindino-2phenylindole (DAPI; Invitrogen).

Image acquisition and analysis. All imaging and analysis for CA3 and CA1 was done by experimenters blind to experiment condition. For CA3, images from coronal sections (approximately $-3.6 \mathrm{~mm}$ anteroposterior from bregma) from four to five slides per subject were taken using the Olympus Scanner VS110 based on a BX61VS upright microscope with a $20 \times$ apochromatic objective (numerical aperture 0.75 ). VS110 scanner software was used to create a virtual $Z$ image of CA3. This method ensured that we assessed cell activity within all of CA3, with a mean \pm SEM of 1009.23 \pm 51.83 and range of 425-1482 total cells counted per subject (Table 1). First, neuronal nuclei, defined as the large, diffusely stained nuclei, were selected. Neither partial cells nor non-neuronal cells, defined as small cells with a $\sim 5 \mu \mathrm{m}$ diameter and brightly stained nuclei, were counted to minimize sampling error. Then a threshold detection
Table 1. Mean \pm SEM cells counted in CA3 and CA1 of different experiment groups

\begin{tabular}{ccccc}
\hline & \multicolumn{1}{c}{$\mathrm{ArC}^{+}$} & \multicolumn{1}{c}{$\mathrm{H1a}^{+}$} & \multicolumn{1}{c}{$\mathrm{ArCH}^{+} \mathrm{Ha}^{+}$} & \multicolumn{1}{l}{ Total } \\
\hline CA3 & & & \\
CC & $12.30 \pm 7.72$ & $33.13 \pm 11.91$ & $1.61 \pm 1.28$ & $795 \pm 135.11$ \\
SAL & $163.84 \pm 27.64$ & $156.55 \pm 21.47$ & $48.76 \pm 8.80$ & $1069 \pm 88.74$ \\
LPS & $192.34 \pm 23.63$ & $208.63 \pm 33.26$ & $75.23 \pm 10.66$ & $1055.67 \pm 93.48$ \\
ND & $182.8 \pm 21.39$ & $197.34 \pm 52.83$ & $68.22 \pm 13.94$ & $1001 \pm 105.97$ \\
CA1 & & & & \\
CC & $16.25 \pm 4.75$ & $36.50 \pm 8.27$ & $0.75 \pm 0.48$ & $772.25 \pm 67.84$ \\
SAL & $202.75 \pm 49.98$ & $192.63 \pm 37.76$ & $54.40 \pm 13.67$ & $1094.63 \pm 168.29$ \\
LPS & $184.44 \pm 36.99$ & $185 \pm 69.38$ & $59.68 \pm 10.49$ & $1116.56 \pm 138.13$ \\
ND & $206 \pm 29.44$ & $249 \pm 69.38$ & $81 \pm 19.32$ & $1094.63 \pm 168.29$ \\
\hline
\end{tabular}

The values indicate the mean $\pm \mathrm{SEM}$ number of $\mathrm{ArC}^{+}, \mathrm{H1a}^{+}, \mathrm{Arc} / \mathrm{Hla}^{+}$(Double ${ }^{+}$), and total cells counted per rat in each experiment group for both CA3 and CA1. The actual number of $\mathrm{Arc}^{+}, \mathrm{H}^{+}{ }^{+}, \mathrm{ArC}_{\mathrm{H}} 1 \mathrm{a}^{+}$, and total cells were used to calculate the proportion of cells active during each of the context presentations and the similarity scores for individual subjects (presented in Fig. 6). CC, Untrained caged control subjects.

was used to determine whether cells were negative (no transcription foci), $\mathrm{Arc}^{+}$(containing only Arc transcription foci), $\mathrm{Hla}^{+}$(containing only Hla transcription foci), or $\mathrm{Arc} / \mathrm{Hla}^{+}$(containing transcription foci for $\mathrm{Arc}$ and H1a) (NIH ImageJ).

The cell layer in CA1 has a high density, and thus the aforementioned imaging and cell counting method would not yield accurate measurements. Therefore, we took confocal image stacks of CA1 from coronal sections (approximately $-3.6 \mathrm{~mm}$ anteroposterior from bregma). They were collected at a $Z$ frequency of $1 \mu \mathrm{m}$ with a Zeiss Axiovert $200 \mathrm{M}$ inverted microscope using a $20 \times$ apochromat objective (numerical aperture 0.8), a CARVII spinning disk confocal unit (BD Biosciences), a CCD camera (ORCA ERII; Hamamatsu), and MetaMorph imaging software (Molecular Devices). For each rat, image stacks for three nonoverlapping fields from CA1 were acquired per slide for four or five slides, allowing for random sampling of labeled cells in CA1. Cell counting for Arc/H1a catFISH was performed as described previously (Vazdarjanova and Guzowski, 2004). Briefly, we counted neuronal nuclei in the median $20 \%$ of each stack, to minimize sampling error attributable to partial cells. The mean \pm SEM number of cells for CA1 was $1158.73 \pm$ 77.02 per rat, and the range was 588-1816 (Table 1). An experimenter blind to behavioral conditions of the subjects selected cells as being negative (no transcription foci), $\mathrm{Arc}^{+}$(containing only Arc transcription foci), $\mathrm{Hla}^{+}$ (containing only $\mathrm{Hla}$ transcription foci), or $\mathrm{Arc} / \mathrm{Hla}^{+}$(containing transcription foci for Arc and H1a).

A similarity score, described previously by Vazdarjanova and $\mathrm{Gu}-$ zowski (2004), was calculated for CA3 and CA1 for each subject. The values of negative, $\mathrm{Arc}^{+}, \mathrm{Hla}^{+}$and $\mathrm{Arc} / \mathrm{Hla}^{+}\left(\right.$Double $\left.^{+}\right)$were used to compute the similarity score, with a value of 0 indicating two statistically independent populations and a value of 1 indicating a single neuronal population activated during both epochs (context presentations). The cells active in epoch 1 are the sum of $\mathrm{HIa}^{+}$and $\mathrm{ArC} / \mathrm{HIa}^{+}$cells; the cells active in epoch 2 are the sum of $\mathrm{Arc}^{+}$and $\mathrm{Arc} / \mathrm{Hla}^{+}$cells. The similarity score is as follows: (Double ${ }^{+}-$Chance)/(Least Epoch - Chance), wherein Chance $=$ Epoch $1 \times$ Epoch 2 and Least Epoch is the smaller of the ensembles activated during epoch 1 or epoch 2 . The denominator term normalizes activity differences, thereby permitting assessment of ensemble overlap even when epoch activity levels vary across subjects or brain regions.

\section{Results}

\section{Time course of cytokine expression in dorsal hippocampus} after systemic LPS administration

Rats were injected (intraperitoneally) with LPS (167 $\mu \mathrm{g} / \mathrm{kg})$ or SAL and then killed 3,6 , or 9 h later ( $n=3$ per group) for assessment of the temporal expression of cytokines in the dorsal hippocampus. We calculated the fold increase in mRNA relative to uninjected home-cage control subjects $(n=4)$ for the cytokines IL- $1 \beta$, TNF- $\alpha$, and IL- 6 , with $\beta$-actin serving as a housekeeping control gene (Fig. 1). Two-way ANOVAs were used for 

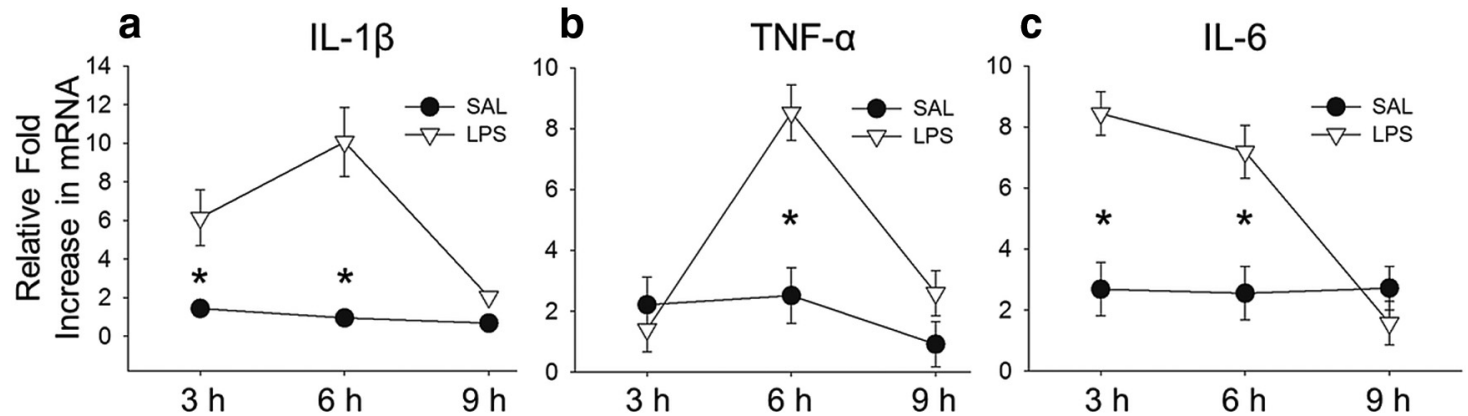

Figure 1. Cytokine expression in dorsal hippocampus after systemic LPS administration. Mean fold increase ( \pm SEM) in mRNA expression relative to actin and home-cage control subjects ( $n=$ 4) for proinflammatory cytokines in dorsal hippocampus 3,6 , or $9 \mathrm{~h}$ after intraperitoneal injections of SAL or LPS ( $n=3$ per group). $\boldsymbol{a}$, There was a robust increase in IL- $1 \beta \mathrm{mRNA}$ expression in dorsal hippocampus after LPS administration 3 and $6 \mathrm{~h}$ after injection but not $9 \mathrm{~h}$ later. $\boldsymbol{b}$, TNF- $\alpha$ mRNA levels were significantly elevated in LPS compared with SAL subjects only at the $6 \mathrm{~h}$ time point. $\boldsymbol{c}$, Similar to IL-1 $\beta$, IL-6 mRNA expression in dorsal hippocampus was significantly higher in LPS-treated rats 3 and $6 \mathrm{~h}$ after injection but not $9 \mathrm{~h} \mathrm{later.}{ }^{*} p<0.05$.

a

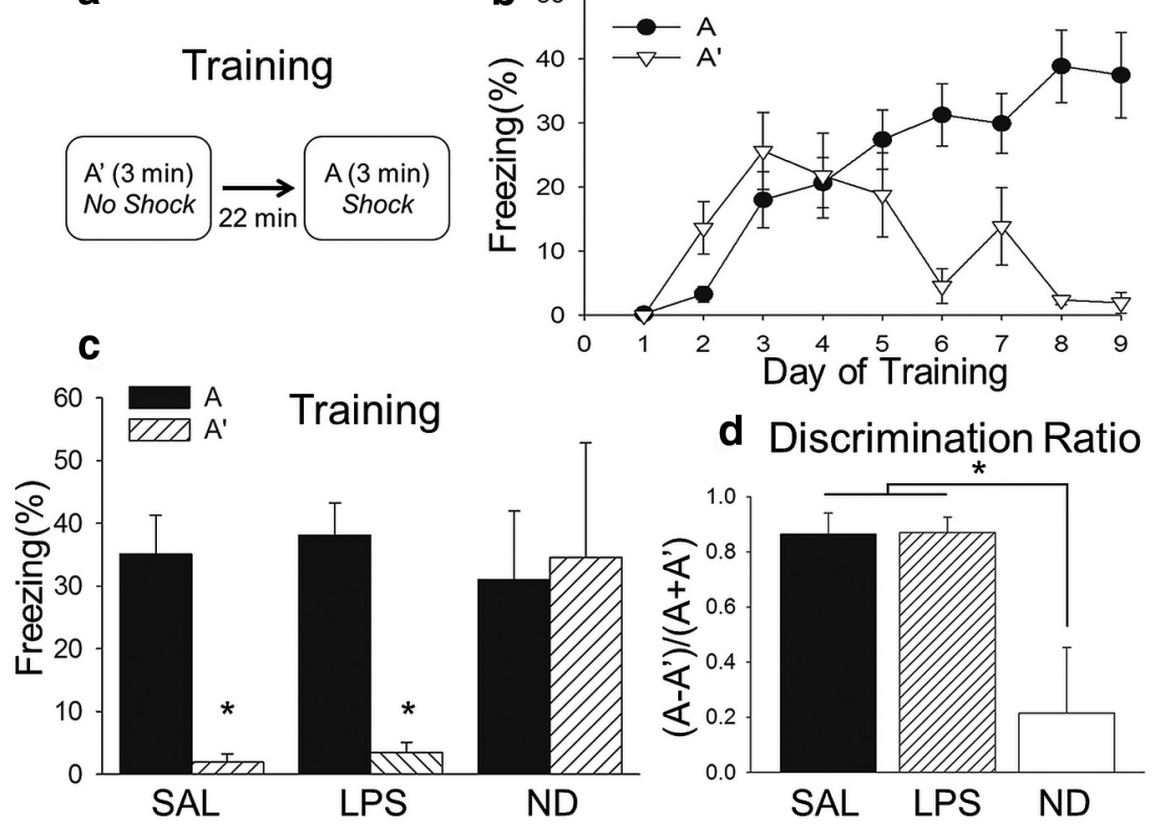

Figure 2. Context discrimination conditioning is intact before systemic LPS administration. $\boldsymbol{a}$, Subjects $(n=22)$ were placed into contexts $A$ and $A^{\prime}$ daily in a pseudorandomized order and received a footshock in context $A$ but not context $A^{\prime}$. $\boldsymbol{b}$, After several days, subjects began to exhibit discriminative freezing to context A. $c$, The mean \pm SEM percentage freezing during the last day of training. Subjects assigned to receive LPS $(n=9)$ or SAL $(n=8)$ the following day exhibited significantly more freezing in context A than context $A^{\prime}$, whereas ND subjects $(n=5)$ did not. $\boldsymbol{d}$, A discrimination ratio [ $\left(\%\right.$ time freezing in $\left.A-A^{\prime}\right) /(\%$ time freezing in $\left.A+A^{\prime}\right)$ ] was calculated for the last day of training. The LPS and SAL groups had significantly higher discrimination ratios than the ND group but did not differ from one another. Therefore, with the exception of the ND group, all subjects reliably expressed robust discriminative conditioning by the end of training, regardless of whether they were assigned to receive systemic administration of SAL or LPS before testing. ${ }^{*} p<0.05$.

statistical analysis, with condition (SAL vs LPS) and time point $(3,6$, or $9 \mathrm{~h})$ as the between-subjects factors.

Collectively, there was an overall increase in cytokine expression after administration of this low dose of LPS. For IL- $1 \beta$, a two-way ANOVA revealed a main effect of condition $\left(F_{(1,17)}=\right.$ $35.35, p<0.001)$ and time point $\left(F_{(2,17)}=7.86, p=0.013\right)$, as well as a significant interaction $\left(F_{(2,17)}=6.72, p=0.019\right)$. There was a robust increase in IL-1 $\beta$ mRNA expression in dorsal hippocampus in subjects that received LPS compared with SAL 3 and $6 \mathrm{~h}$ after injection but not $9 \mathrm{~h}$ later (Holm-Sidak test, $p<0.05$ ). For TNF- $\alpha$, there was a main effect for condition $\left(F_{(1,17)}=13.72\right.$, $p=0.004)$ and time point $\left(F_{(2,17)}=12.83, p=0.002\right)$, as well as a significant interaction $\left(F_{(2,17)}=6.31, p=0.017\right)$. Although there was an overall increase in TNF- $\alpha$ mRNA expression in dorsal hippocampus in subjects that received LPS compared with SAL, the groups were only significantly different from each other $6 \mathrm{~h}$ after injection (Holm-Sidak test, $p<0.05)$. For IL-6, there was a main effect of condition $\left(F_{(1,17)}=25.87, p<0.001\right)$ and time point $\left(F_{(2,17)}=10.13, p=0.004\right)$, as well as a significant interaction $\left(F_{(2,17)}=14.12\right.$, $p=0.001$ ), with elevated IL-6 mRNA expression 3 and $6 \mathrm{~h}$ after LPS administration (Holm-Sidak test, $p<0.05$. The peak expression was at $6 \mathrm{~h}$ for IL- $1 \beta$ and TNF- $\alpha$ and 3 h for IL- 6 ( $p<0.05$; Fig. 1$)$. None of the cytokines measured were elevated $9 \mathrm{~h}$ after LPS injections. Because there was a robust and significant 8 - to10 -fold increase in all three cytokines $6 \mathrm{~h}$ after LPS injections, this time point was used to examine the effect of acute neuroinflammation on context memory retrieval and neural circuit activity.

\section{Acute neuroinflammation impaired context discrimination}

Subjects were trained in a context discrimination conditioning task in which they were placed into contexts $\mathrm{A}$ and $\mathrm{A}^{\prime}$ daily (Fig. 2). They were presented with a brief, mild footshock in context A but not $\mathrm{A}^{\prime}$ and trained until they reached discrimination criterion $(>25 \%$ freezing in context $\mathrm{A}$ and $<10 \%$ in context $\mathrm{A}^{\prime}$ for 2 consecutive days). Figure $2 b$ shows the mean \pm SEM percentage freezing for all subjects up to and including reaching criterion, before pretesting administration of SAL or LPS. The range for individual subjects reaching criterion was 6-9 d, with different subjects receiving injections of SAL $(n=8)$ or LPS $(n=9)$ and testing on days 7-10. There were some subjects that, despite training, did not discriminate between contexts and were assigned to the nondiscrimination group (ND;n=5) and tested (without any injections) on the same days as SAL and LPS subjects.

During the last day of training, a two-way ANOVA revealed a main effect of context $\left(F_{(1,43)}=13.46, p<0.001\right)$ and a 
significant interaction $\left(F_{(2,43)}=3.87\right.$, $p=0.029)$ but not a main effect for condition $\left(F_{(1,93)}=1.39, p=0.16\right)$. Subjects assigned to receive LPS or SAL the following day before testing exhibited significantly more freezing in context A than context $\mathrm{A}^{\prime}$, whereas ND subjects did not exhibit a significant difference in freezing to the two contexts and froze significantly more than SAL or LPS subjects in context $\mathrm{A}^{\prime}$ (Holm-Sidak test, $p<0.05$; Fig. $2 c$ ).

A discrimination ratio [(\% time freezing in $\left.\mathrm{A}-\mathrm{A}^{\prime}\right) /(\%$ time freezing in $\mathrm{A}+$ $\left.A^{\prime}\right)$ ] was calculated for the last day of training. A one-way ANOVA revealed a main effect for condition $\left(F_{(2,21)}=9.26\right.$, $p=0.002$ ), with a significantly higher discrimination ratio in the LPS and SAL groups than the ND group (Holm-Sidak test, $p<0.05)$ but no difference between LPS and SAL (Holm-Sidak test, $p>0.05$; Fig. $2 d$ ). Therefore, with the exception of the ND group, all subjects reliably expressed robust discriminative conditioning, indicating that the task was well learned before systemic administration of SAL or LPS and testing.

Context discrimination testing occurred $24 \mathrm{~h}$ after the last day of training, with LPS or SAL injections administered $6 \mathrm{~h}$ before testing (Fig. 3a). A two-way ANOVA revealed a significant interaction $\left(F_{(2,43)}=4.79, p=0.014\right)$ but not a main effect for condition $\left(F_{(2,43)}=0.394, p=\right.$ $0.677)$ nor a main effect for context $\left(F_{(1,43)}\right.$ $=1.75, p=0.193)$. SAL subjects continued to freeze significantly more in context A than context $\mathrm{A}^{\prime}$ (Holm-Sidak test, $p<$ $0.05)$, whereas groups LPS and ND did not (Holm-Sidak test, $p>0.05$; Fig. 3b). Additionally, although there were no significant group differences in freezing to context A, LPS and ND subjects exhibited significantly more freezing in context $\mathrm{A}^{\prime}$ than SAL subjects (Holm-Sidak test, $p<$ $0.05)$. There was a main effect for discrimination ratio during testing $\left(F_{(2,21)}=\right.$ $15.82, p<0.001$; Fig. $3 c)$, with a significantly higher discrimination ratio in the SAL group than the LPS and ND groups (Holm-Sidak test, $p<0.05$ ), which were not different from each other (Holm-Sidak test, $p>0.05)$. Therefore, systemic administration of LPS disrupted the retrieval of context discrimination memory.

It is noteworthy to point out that, although all subjects in the SAL group exhibited higher freezing in context $A$ than context $A^{\prime}$ during testing, individual subjects in both the LPS and ND groups froze either in both contexts $\mathrm{A}$ and $\mathrm{A}^{\prime}$ or in neither of the contexts (Fig. 3d). Thus, although all LPS subjects expressed an inability to discriminate, some generalized to the context paired context $\mathrm{A}^{\prime} .{ }^{*} p<0.05$.
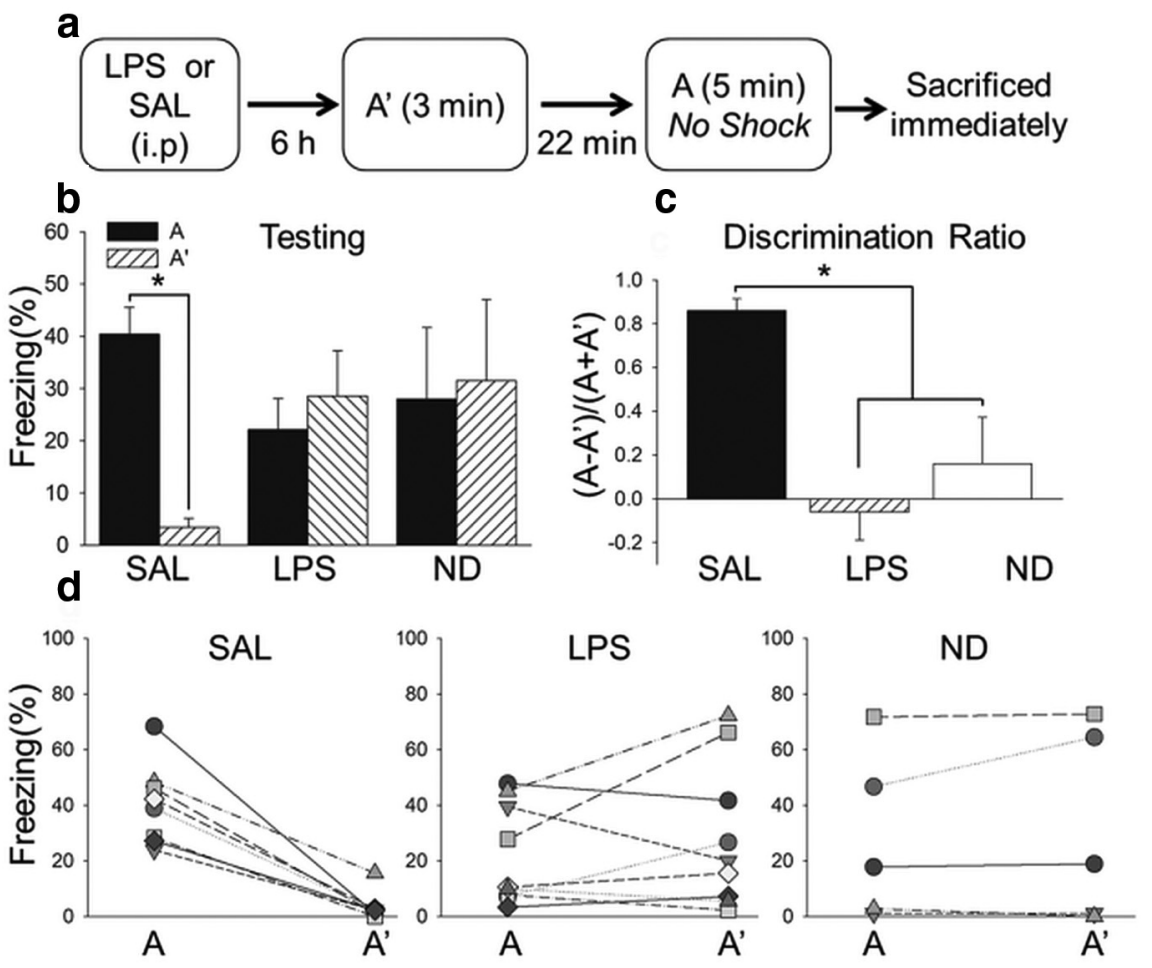

Figure 3. Acute neuroinflammation dramatically impaired context discrimination. $\boldsymbol{a}$, Experimental design for testing. $\boldsymbol{b}$, The mean \pm SEM percentage freezing during testing. SAL subjects $(n=8)$ exhibited significantly more freezing in context A than context A' during testing, whereas LPS $(n=9)$ and ND $(n=5)$ subjects did not. $c$, The discrimination ratio during testing was significantly higher in the SAL group than the LPS and ND groups, which did not differ from each other. $\boldsymbol{d}$, Freezing scores for individual subjects in contexts $A$ and $A^{\prime}$. All subjects in the SAL group exhibited higher freezing in context $A$ than context $A^{\prime}$ during testing, whereas individual subjects in both the LPS and ND groups froze either in both contexts $A$ and $A^{\prime}$ or in neither context $A$ nor

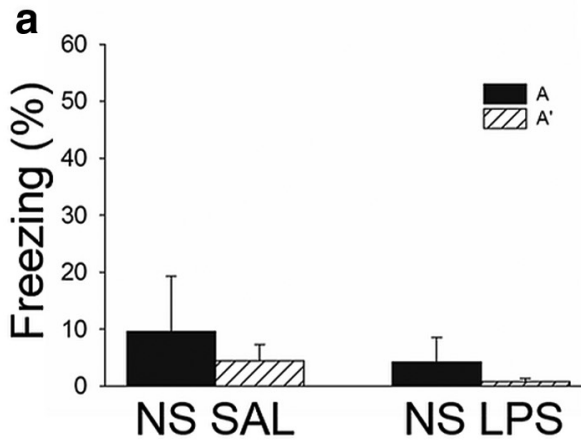

b

Figure 4. LPS administration did not affect locomotor activity or retrieval of strong simple context fear conditioning. $\boldsymbol{a}$, Mean \pm SEM percentage freezing during testing for subjects exposed to environments $A$ and $A^{\prime}$ daily but never presented with a footshock. They were tested on the same day as subjects trained in context discrimination conditioning and injected (intraperitoneally) with SAL $(n=3)$ or LPS $(n=4) 6 \mathrm{~h}$ before testing. Neither group exhibited high levels of freezing to either context during testing, indicating that LPS administration did not decrease levels of locomotor activity or exploration. $\boldsymbol{b}$, Mean \pm SEM percentage freezing during testing for subjects trained in a single context fear conditioning session and administered SAL or LPS $6 \mathrm{~h}$ before a 5 min testing session in the training context. Both SAL- and LPS-treated rats exhibited a robust level of freezing during testing, indicating that acute neuroinflammation did not disrupt the retrieval of simple context fear conditioning.

with shock, whereas others generalized to the context that was not paired with shock. This is important because, at specific doses, LPS can induce lethargy and hypoactivity (Henry et al., 2008), which can be problematic when using freezing as an index of learning. However, the low dose of LPS administered in the present study did not affect locomotor activity or exploration. If LPS attenuated locomotor activity, then all subjects injected with LPS should have exhibited high levels of freezing or hypoactivity 
a

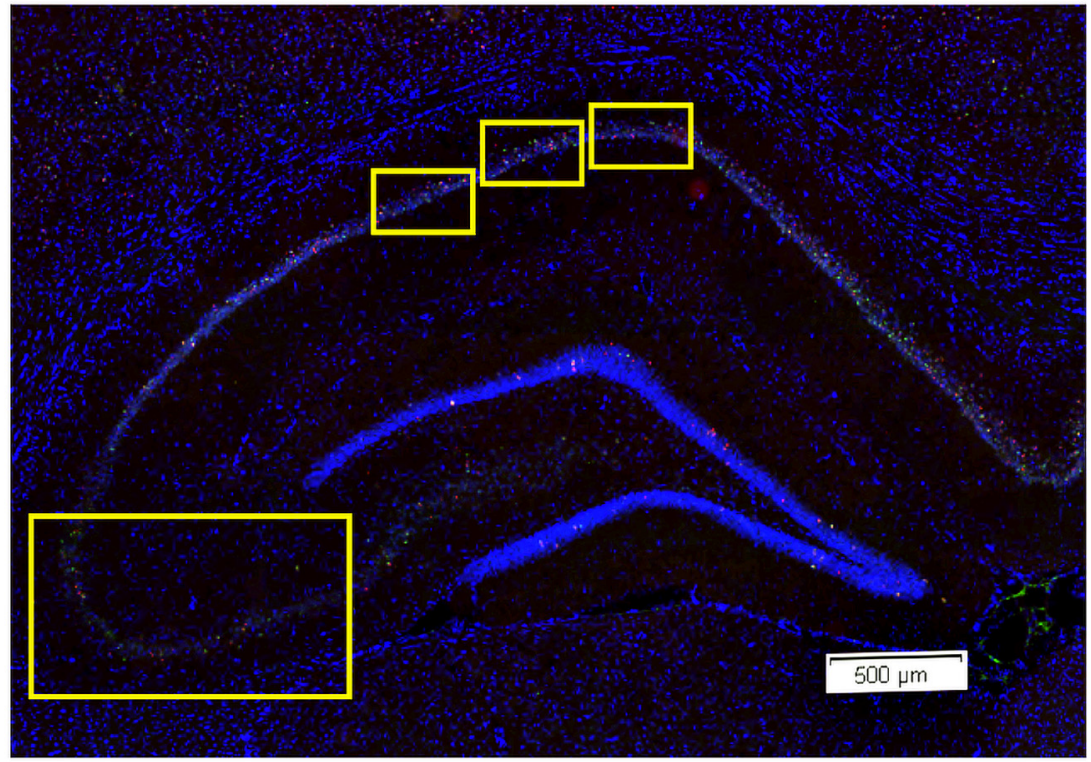

b

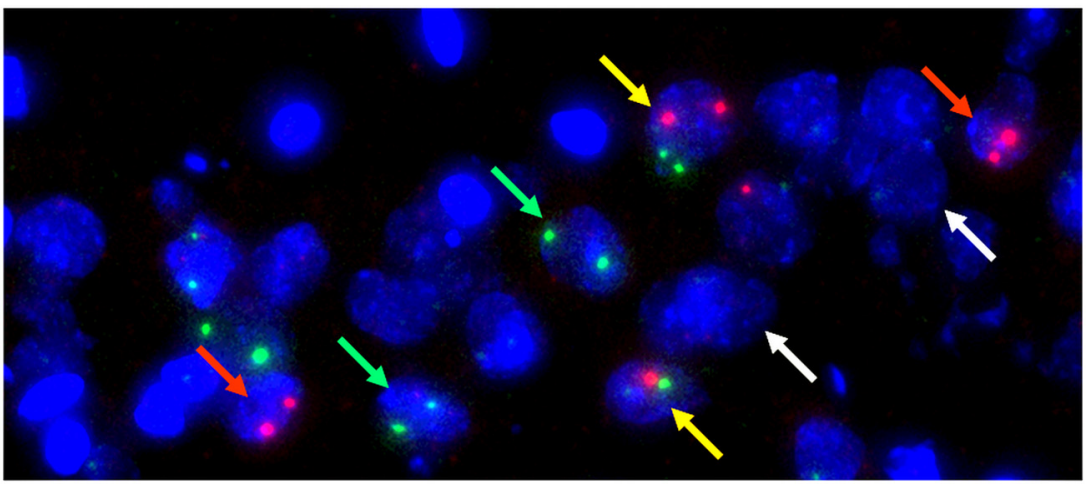

Figure 5. IEG expression in dorsal hippocampus. $\boldsymbol{a}$, Low-magnification image of DAPI-stained dorsal hippocampus indicating the fields imaged for CA1 and CA3. The relative positions analyzed for CA1 (top) and CA3 (bottom, left) are indicated by yellow boxes. $\boldsymbol{b}$, Representative $20 \times$ projection image of CA3 from an SAL-treated rat trained in context discrimination conditioning, showing $\mathrm{Arc}^{+}$(red arrows), $\mathrm{Hla}^{+}$(green arrows), $\mathrm{ArC} \mathrm{Hla}^{+}$(yellow arrows), and negative (white arrows) neurons

in both contexts. Additionally, separate subjects that were exposed to both contexts daily but never shocked were injected with SAL $(n=3$; NS SAL) or LPS ( $n=4$; NS LPS $)$ and tested on the same day as trained subjects. These subjects did not exhibit freezing or hypoactivity during testing (Fig. $4 a$ ), supporting the notion that any observed behavioral differences in trained (i.e., shocked) LPS subjects was not attributable to lethargy or any other nonspecific effect of LPS on locomotor activity. Because LPS administration can also disrupt motivation (Henry et al., 2008), which could interfere with the ability to express a fear response, separate subjects were trained in one 6 min session of a contextual fear conditioning paradigm consisting of three footshocks $(1 \mathrm{~mA}, 2 \mathrm{~s})$ that resulted in robust conditioning. They were tested the following day $6 \mathrm{~h}$ after receiving intraperitoneal injections of SAL $(n=9)$ or LPS $(n=11)$. All subjects exhibited high levels of freezing during test, independent of whether they received SAL or LPS $\left(t_{(18)}=0.763, p=0.455\right.$; Fig. $\left.4 b\right)$. Therefore, the low dose of LPS used here did not disrupt locomotor activity, motivation, or the ability to retrieve a strong fear memory but did dramatically impair context discrimination memory retrieval.

\section{Acute neuroinflammation altered hippocampal} network activity

We used Arc/Hla catFISH to visualize and compare neural circuit activity in CA3 and CA1 during testing (Fig. 5a). A representative image of CA3 from an SAL-treated subject shows the distinct cellular patterns of IEG transcription detected using Arc/Hla catFISH (Fig. 5b). Nuclei with $\mathrm{H} \mathrm{a}^{+}$transcription foci indicate neurons active $\sim 30$ min before the animal's death (during exposure to context $\mathrm{A}^{\prime}$ ), whereas nuclei with $\mathrm{Arc}^{+}$transcription foci indicate neurons active within $\sim 5 \mathrm{~min}$ of the animal's death (during exposure to context A; Vazdarjanova et al., 2002). Thus, nuclei containing both $\mathrm{Arc}^{+}$and $\mathrm{Hla}^{+}$foci (Arc) $\mathrm{H} \mathrm{a}^{+}$) were active during both behavioral epochs (exposure to contexts $\mathrm{A}$ and $\mathrm{A}^{\prime}$ ). The mean \pm SEM of actual numbers of $\mathrm{Arc}^{+}, \mathrm{Hla}^{+}, \mathrm{Arc} / \mathrm{Hla}^{+}$, and total cells counted per experiment group are presented in Table 1. Figure 6 shows the percentage of nuclei active only during context $\mathrm{A}^{\prime}$ exposure $\left(\mathrm{Hla}^{+}\right.$only), only during context A exposure ( $A r c^{+}$only), or during exposure to both contexts (Arc) $\mathrm{H} \mathrm{a}^{+}$), for CA3 (Fig. 6a) or CA1 (Fig. 6b). A one-way ANOVA revealed a main effect for experiment group in CA3 $\left(F_{(3,77)}=\right.$ $18.71, p<0.001$; Fig. $6 a)$ and CA1 $\left(F_{(3,77)}\right.$ $=17.85, p<0.001$; Fig. $6 b)$, with all trained groups having significantly elevated gene expression compared with home-cage controls but not differing from one another (Holm-Sidak test, $p<$ 0.05). Thus, exposure to the two contexts induced a significant increase in $\operatorname{Arc}$ and H1a expression in both CA3 and CA1 regions.

These raw count values were then used to determine the proportion of cells active during the two context exposures. The mean \pm SEM percentage of all cells active during exposure to context $\mathrm{A}^{\prime}\left(\mathrm{H}_{1} \mathrm{a}^{+}\right.$and $\left.\mathrm{Arc} / \mathrm{H} \mathrm{a}^{+}\right)$or context $\mathrm{A}\left(\mathrm{Arc}^{+}\right.$and $\left.\mathrm{Arc} / \mathrm{Hla}^{+}\right)$is shown in Figure 6, $c$ and $d$. There was a robust increase in the proportion of all $\mathrm{Hla}^{+}\left(\mathrm{CA} 3, F_{(3,25)}=6.72\right.$, $p=0.002$; CA1, $\left.F_{(3,25)}=9.20, p=0.002\right)$ and all Arc $^{+}$(CA3, $F_{(3,25)}=14.58, p<0.001$; CA1, $\left.F_{(3,25)}=10.71, p<0.001\right)$ cells in the trained groups relative to untrained home-cage control subjects but no significant differences in the proportion of cells with $\mathrm{Arc}^{+}$or $\mathrm{H}^{+} \mathrm{a}^{+}$foci in CA3 or CA1 among the trained groups (Holm-Sidak test, $p>0.05$ ), demonstrating that immune challenge did not disrupt IEG transcription in CA3 or CA1.

To assess ensemble overlap in the different treatment groups, it is necessary to normalize the raw cell count values because the chance overlap varies depending on total activity, which differs among subjects within and between groups. Accordingly, a similarity score was calculated for each subject, allowing a direct comparison of neuronal ensemble overlap independent of overall activity levels (Vazdarjanova and Guzowski, 2004; Burke et al., 2005; Rosi et al., 2009; Niibori et al., 2012). The values of negative, $\mathrm{Arc}^{+}, \mathrm{Hla}^{+}$, and $\mathrm{Arc} / \mathrm{Hla}^{+}$cell proportions were used to compute the similarity score, which takes into account the actual proportions and probability of cells active during the two behavioral epochs for individual subjects. A similarity score of 0 indicates two statistically independent populations, and a value of 1 indicates a single neuronal population activated during both be- 
havioral epochs (context presentations). Thus, subjects that discriminated between contexts would likely have lower similarity scores, i.e., less overlap in neuronal ensembles, than subjects that generalized. The similarity score measures for CA 3 and CA1 are shown in Figure 6, $e$ and $f$. A oneway ANOVA revealed a main effect for experimental group in CA3 $\left(F_{(2,21)}=\right.$ $6.72, p=0.006)$ and CA1 $\left(F_{(2,21)}=9.31, p\right.$ $=0.002)$. Specifically, the similarity scores for LPS and ND were significantly higher than SAL (Holm-Sidak test, $p<$ $0.05)$ but were not different from each other (Holm-Sidak test, $p>0.05$ ) for both hippocampus subfields. Therefore, both LPS and ND subjects, which did not discriminate between contexts $\mathrm{A}$ and $\mathrm{A}^{\prime}$, had a greater overlap in hippocampal neuronal ensembles in both CA 3 and CA 1 than SAL subjects that did discriminate. Additionally, a direct comparison between LPS and SAL groups only also revealed a significant difference in similarity score for both CA3 $\left(t_{(15)}=3.37, p=\right.$ $0.004)$ and CA1 $\left(t_{(15)}=3.62, p=0.002\right)$. Collectively, these data indicate the following: (1) there is a link between neuronal ensemble activity in the hippocampus and context discrimination; and (2) acute neuroinflammation did not disrupt transcriptional activation of hippocampal neurons but did alter the specific neuronal ensembles activated during exposure to behaviorally relevant contexts.

CA1 neuronal ensemble activity after a single exposure to contexts A and $A^{\prime}$ does not differ from trained LPStreated subjects

In an independent experiment, separate rats were given a single exposure to environments $\mathrm{A}$ and $\mathrm{A}^{\prime}$ (group SE; $n=4$ ). The contexts and behavioral protocol were the same as the testing session for the aforementioned context discrimination conditioning paradigm. We used $\mathrm{Arc} / \mathrm{Hla}^{+}$ catFISH to assess neural circuit activity in CA1 to determine the initial overlap in hippocampal neuronal ensembles to these two similar contexts before context discrimination conditioning. The proportion of CA1 neurons active during exposure to context $\mathrm{A}^{\prime}\left(\mathrm{H}_{1} \mathrm{a}^{+}\right.$and $\mathrm{Arcl}$ $\mathrm{Hla}^{+}, 22.8 \pm 0.61 \%$, mean $\left.\pm \mathrm{SEM}\right)$ and context $\mathrm{A}\left(\mathrm{Arc}^{+}\right.$and $\mathrm{Arc} / \mathrm{H} \mathrm{a}^{+}, 20.78 \pm 0.96 \%$, mean \pm SEM) were not significantly different from those in the SAL, LPS, and ND groups in the context discrimination conditioning experiment (all $\mathrm{H}_{1} \mathrm{a}^{+}$, $F_{(3,25)}=1.61, p=0.215$; all $\left.\operatorname{Arc}^{+}, F_{(3,25)}=1.29, p=0.30\right)$. There was a significant difference in similarity score measure for CA1 ensembles of rats in the SE, SAL, and LPS groups $\left(F_{(2,20)}=9.631\right.$, $p=0.001)$. Specifically, the similarity score for rats after a single exposure to contexts $\mathrm{A}$ and $\mathrm{A}^{\prime}$ was significantly higher than
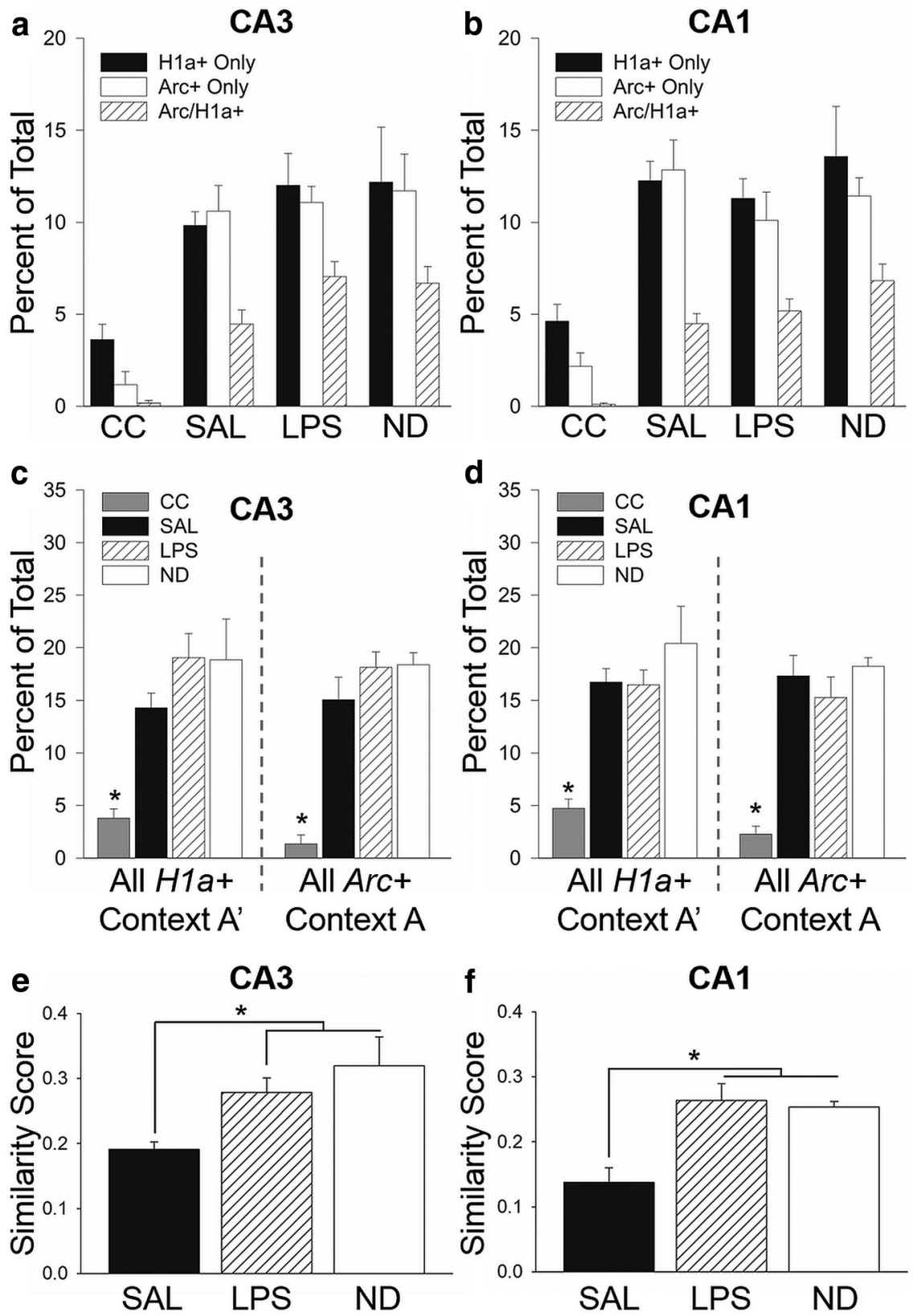

Figure 6. Acute neuroinflammation altered neuronal ensemble activity in the hippocampus. The mean \pm SEM percentage of $\mathrm{Arc}^{+}, \mathrm{H1a}^{+}$, or $\mathrm{Arc} / \mathrm{HIa}^{+}$cells in CA3 (a) and CA1 (b). The mean \pm SEM percentage of cells active during exposure to context $\mathrm{A}^{\prime}$ $\left(\mathrm{H} \mathrm{a}^{+}\right.$and $\left.\mathrm{Arc} / \mathrm{H} \mathrm{a}^{+}\right)$and context A $\left(\mathrm{Arc}^{+}\right.$and $\left.\mathrm{Arc} / \mathrm{H} a^{+}\right)$in $\mathrm{CA} 3(\boldsymbol{c})$ and $\mathrm{CA} 1$ (d). There was a robust increase in the proportion of cells with $\mathrm{Arc}^{+}$and $\mathrm{HIa}^{+}$foci in trained subjects compared with home-cage controls $(n=4)$ in both hippocampal subfields, with no significant differences among the trained groups. A similarity score was calculated for each subject, with a value of 0 indicating two statistically independent populations and a value of 1 indicating a single neuronal population activated during both context presentations. The similarity scores for LPS $(n=9)$ and ND $(n=5)$ subjects were significantly higher than SAL subjects $(n=8)$ in both CA3 $(\boldsymbol{e})$ and CA1 $(\boldsymbol{f})$. These data suggest that acute neuroinflammation degrades the orthogonal representation in CA3 and CA1 to distinct but similar contexts. ${ }^{*} p<0.05$. CC, Untrained caged control subjects.

trained SAL subjects (Holm-Sidak test, $p<0.05$ ) but not different from the nondiscriminating LPS subjects (Holm-Sidak test, $p<0.05$; Fig. 7). The difference in similarity scores between the SE and trained, discriminating SAL groups supports the notion that there is an active process that increases orthogonalization for the ensemble representations of contexts $\mathrm{A}$ and $\mathrm{A}^{\prime}$ over the course of training in context discrimination conditioning. In contrast, the similarity scores for the SE and LPS rats were indistinguishable. Although these data are from separate experiments, 


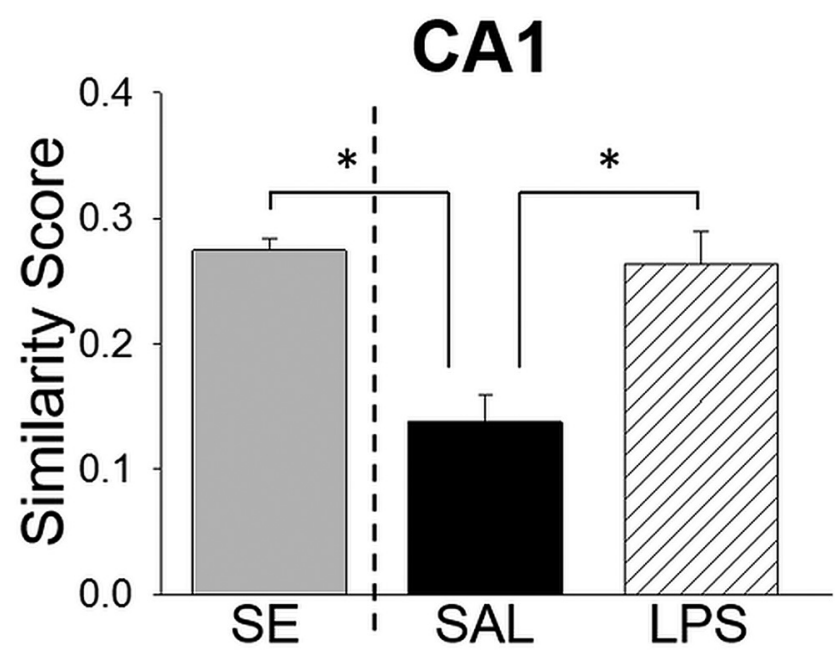

Figure 7. Similarity score for CA1 neuronal ensembles after a single exposure to the two training contexts does not differ from LPS-treated subjects. The similarity scores from SAL and LPS subjects from the context discrimination conditioning experiment (right of the dashed line) and from a group that received a single exposure to contexts $A^{\prime}$ and $A$ (without footshock presentation) from a separate experiment. SE rats had a higher similarity score compared with trained SAL subjects that exhibited robust context discrimination, indicating that hippocampal neuronal ensembles are actively orthogonalized as a consequence of training. The similarity scores for LPS rats that were impaired in context discrimination and SE rats did not differ, suggesting that neuroinflammation impaired pattern separation processes in the hippocampus.

they raise the intriguing possibility that the neuronal ensembles for contexts A and $\mathrm{A}^{\prime}$ in the hippocampus of LPS rats were similar to SAL subjects at the end of training (before LPS administration) but that they returned to their initial level of overlap (similarity score after SE) during acute neuroinflammation. Collectively, the cell activity data suggest that the orthogonal CA1 and CA3 ensembles for contexts $\mathrm{A}$ and $\mathrm{A}^{\prime}$ in the SAL rats support context discrimination and that acute neuroinflammation impairs this pattern separation process, thus abolishing discrimination in the LPStreated rats (Fig. 8).

\section{Discussion}

Our data provide compelling support for a dynamic interaction between immune system activation, neural circuit activity, and cognitive function. Systemic LPS administration robustly impaired retrieval of previously learned context discrimination and reduced orthogonalization of neuronal ensembles in the hippocampus. Importantly, this occurred when levels of IL- $1 \beta$, TNF- $\alpha$, and IL- 6 were elevated in dorsal hippocampus, a structure needed for context discrimination (Frankland et al., 1998; Parsons and Otto, 2008). Together, these data indicate that neuroinflammation impairs a specific computational process - pattern separation-required for behavioral context discrimination.

Although there is evidence that proinflammatory cytokines, including IL-1 $\beta$, contribute to normal neural function under basal conditions (Yirmiya and Goshen, 2011), pathological cytokine levels can produce memory deficits (Oitzl et al., 1993; Gibertini et al., 1995). Notably, the forms of memory sensitive to disruption by immunogenic stimuli tend to be hippocampus dependent, such as the spatial water maze task (Gibertini et al., 1995; Arai et al., 2001; Shaw et al., 2001) and contextual, but not cued, fear conditioning (Pugh et al., 1998; Barrientos et al., 2002; Thomson and Sutherland, 2005). Most studies on the effects of inflammation on cognition have examined the effect on memory acquisition or consolidation. In contrast, there are relatively few reports on whether neuroinflammation affects memory retrieval. However, patients with immune disorders, including multiple sclerosis or HIV, can have problems with memory retrieval independent of acquisition or consolidation deficits (Thornton et al., 2002; Woods et al., 2007). As such, memory retrieval problems caused by acute neuroinflammation can be as disruptive to cognitive function as acquisition or consolidation deficits. Therefore, the consequence of neuroinflammation on memory retrieval needs additional elucidation.

Determining the specific nature of cognitive dysfunction during neuroinflammation is difficult, especially because many immune disorders result in chronically elevated cytokine levels. By using an acute immune challenge, we can eliminate some of the problems associated with chronic inflammation and dissect the effect of immune activation on different memory stages. Still, sickness behaviors arising from acute neuroinflammation may confound the interpretation of behavior during retrieval. For instance, at specific doses, LPS can induce lethargy and hypoactivity (Henry et al., 2008), which can be problematic when using freezing as an index of learning. However, the low dose of LPS used here did not affect locomotor activity or exploration (Fig. 4a). Furthermore, rats trained in standard context fear conditioning and administered LPS before retrieval exhibited robust freezing during testing (Fig. 4b), suggesting that this low dose of LPS leaves motivational processes necessary for the fear response intact. Therefore, this acute low dose of LPS enabled us to examine the effect of immune activation on retrieval of context discrimination memory. Here, to the best of our knowledge, we provide the first evidence of a dramatic impairment in the retrieval of a well learned context discrimination task during acute neuroinflammation.

Whereas a similar dose of LPS given immediately after context fear conditioning impairs memory consolidation (Pugh et al., 1998), our findings reveal a critical sensitivity in retrieval of context discrimination but not standard context fear conditioning. The apparent disparity between the effect of LPS on context fear conditioning in these studies indicates that LPSinduced neuroinflammation differentially affects molecular mechanisms necessary for consolidation versus retrieval. For example, systemic LPS administration (Kranjac et al., 2012) or direct intrahippocampal injection of IL- $1 \beta$ leads to downregulation of BDNF (Barrientos et al., 2004), a molecule strongly linked to consolidation of LTP (Bramham and Messaoudi, 2005) within the hippocampus. As such, neuroinflammation could specifically disrupt LTP-like processes needed during the consolidation period separate from processes required for retrieval.

Similar to the lack of effect of LPS on retrieval of context fear conditioning observed here, others have reported intact working memory during retrieval of a spatial alternation task after systemic LPS administration (Field et al., 2012; Griffin et al., 2013). These data suggest that neuroinflammation does not impair previously consolidated memories, yet we observed a robust impairment in context discrimination retrieval. Why would LPS administration impair retrieval of one form of hippocampusdependent memory and not another? One explanation for this discrepancy lies in the nature of the computation needed to perform retrieval in these different behavioral paradigms. Context discrimination conditioning taxes the ability to discriminate between two similar contexts sharing many features and requires a 
computational process that context fear conditioning does not, namely pattern separation.

The ability to form or retrieve discrete representations, which is necessary for successful context discrimination, is thought to occur via pattern separation processes. Through the use of context discrimination conditioning and $\mathrm{Arcl}$ Hla catFISH imaging, we linked hippocampal neural circuit function to context memory discrimination. Control subjects had low CA3 and CA1 similarity scores and robust discrimination, consistent with the notion that pattern separation at the neural level underlies context discrimination at the behavioral level. Conversely, LPS administration resulted in significantly higher CA3 and CA1 similarity scores, indicating a greater overlap in neuronal ensembles activated in contexts $A$ and $A^{\prime}$. This difference arose although both groups experienced the same context exposures and the same number, duration, and intensity of shock presentations. The only difference was whether they were injected with SAL or LPS before testing, which did not affect the overall proportions of neurons expressing Arc and H1a but did alter the pattern of IEG expression in neuronal ensembles activated by exposure to different contexts. Notably, both LPS and ND subjects had significantly higher similarity scores than SAL subjects, and neither group behaviorally discriminated. Thus, the context discrimination deficit during acute neuroinflammation is likely attributable to the degradation of the orthogonal CA 1 and CA 3 representations for the distinct, but similar, contexts (i.e., impaired pattern separation), leading to context generalization (Fig. 8).

In the present study, we observed a greater overlap in neuronal ensemble activity in both CA3 and CA1 of LPS-treated rats, suggesting that neuroinflammation disrupts circuit function within both subfields. Although we could not use Arc/H1a catFISH to assess circuit activity in DG (see Materials and Methods), we focused on CA3 because DG projects to CA3 and both regions have been implicated in pattern separation (Leutgeb et al., 2007). For example, reducing adult neurogenesis in DG impairs orthogonalization of similar (but not dissimilar) contexts in CA3 (Niibori et al., 2012). Given the high density of cytokine receptors in DG (Lechan et al., 1990; Schöbitz et al., 1992), a strong possibility is that altered granule cell activity attributable to neuroinflammation may be responsible for the disruption in neural circuit activity in CA3 and CA1. The output from CA3 is passed to CA1, which, ultimately, is the main output of the hippocampus, and subtle changes in neural circuit activity could potentially have dramatic effects on behavior, as demonstrated here. Alternatively, cortical inputs coming into the hippocampus may be altered, thus affecting both CA3 and CA1, or neural processing within CA3 may be disrupted and this altered signal is sent to CA 1 , which cannot "correct" it. Future studies will be required to differentiate between these potential network level explanations for the observed altered CA3 and CA1 ensemble activity.
The current findings are partially consistent with a previous study using Arc catFISH in which LPS disrupted circuit activity in CA3 but not CA1 (Rosi et al., 2009). Given the large number of differences in these studies with respect to LPS dose, route of administration (intracerebroventricular vs intraperitoneal), timing (chronic vs acute), and behavior (encoding of two novel neutral contexts vs retrieval of well learned context discrimination), it is difficult to reconcile the apparent discrepancy observed in CA1. However, both studies show a clear effect of LPS on neuronal ensemble activation in CA3, further supporting a susceptibility of hippocampal processing to neuroinflammation. Nonetheless, the data presented here are the first to show that hippocampal circuit activity and context discrimination memory can be significantly altered after mild acute neuroinflammation.

Some researchers have posited that information-processing circuits in the hippocampus change with age (Wilson et al., 2006). Consistent with that notion, there is a decline in pattern separation activity within aged humans using fMRI (Yassa et al., 2011), potentially explaining why older people have difficulty learning new information and only remember gist information. Importantly, there is an increase in neuroinflammation attributable to aging that coincides with cognitive decline (Yaffe et al., 2003; Sparkman and Johnson, 2008; Burton and Johnson, 2012). Together with the present study, these data suggest that inflammation may affect cognition by altering activity of specific neural circuits. Moreover, the current findings show that dysregulation of specific neural circuits can occur even in transient neuroinflammation, in the absence of gross changes in integrity of gray or white matter.

Our findings indicate that low-level neuroinflammation impairs memory retrieval functions that specifically require pattern separation. By assessing the impact of an immune challenge on both behavior and neural circuit activity, this study advances understanding of the dynamic interaction between the immune 
and nervous systems. This integrative approach can be used to further answer questions regarding the effect of chronic versus acute immune activation, how neuroinflammation affects other memory processes, and, importantly, if blocking the immune response in the brain can restore cell network activity and cognitive function.

\section{References}

Albensi BC, Mattson MP (2000) Evidence for the involvement of TNF and NF-kappaB in hippocampal synaptic plasticity. Synapse 35:151-159. CrossRef Medline

Alme CB, Buzzetti RA, Marrone DF, Leutgeb JK, Chawla MK, Schaner MJ, Bohanick JD, Khoboko T, Leutgeb S, Moser EI, Moser MB, McNaughton BL, Barnes CA (2010) Hippocampal granule cells opt for early retirement. Hippocampus 20:1109-1123. CrossRef Medline

Arai K, Matsuki N, Ikegaya Y, Nishiyama N (2001) Deterioration of spatial learning performances in lipopolysaccharide-treated mice. Jpn J Pharmacol 87:195-201. CrossRef Medline

Barrientos RM, Higgins EA, Sprunger DB, Watkins LR, Rudy JW, Maier SF (2002) Memory for context is impaired by a post context exposure injection of interleukin-1 beta into dorsal hippocampus. Behav Brain Res 134: 291-298. CrossRef Medline

Barrientos RM, Sprunger DB, Campeau S, Watkins LR, Rudy JW, Maier SF (2004) BDNF mRNA expression in rat hippocampus following contextual learning is blocked by intrahippocampal IL-1beta administration. J Neuroimmunol 155:119-126. CrossRef Medline

Bassi GS, Kanashiro A, Santin FM, de Souza GE, Nobre MJ, Coimbra NC (2012) Lipopolysaccharide-induced sickness behaviour evaluated in different models of anxiety and innate fear in rats. Basic Clin Pharmacol Toxicol 110:359-369. CrossRef Medline

Beattie EC, Stellwagen D, Morishita W, Bresnahan JC, Ha BK, Von Zastrow M, Beattie MS, Malenka RC (2002) Control of synaptic strength by glial TNFalpha. Science 295:2282-2285. CrossRef Medline

Bramham CR, Messaoudi E (2005) BDNF function in adult synaptic plasticity: the synaptic consolidation hypothesis. Prog Neurobiol 76:99-125. CrossRef Medline

Burke SN, Chawla MK, Penner MR, Crowell BE, Worley PF, Barnes CA, McNaughton BL (2005) Differential encoding of behavior and spatial context in deep and superficial layers of the neocortex. Neuron 45:667674. CrossRef Medline

Burton MD, Johnson RW (2012) Interleukin-6 trans-signaling in the senescent mouse brain is involved in infection-related deficits in contextual fear conditioning. Brain Behav Immun 26:732-738. CrossRef Medline

Chawla MK, Guzowski JF, Ramirez-Amaya V, Lipa P, Hoffman KL, Marriott LK, Worley PF, McNaughton BL, Barnes CA (2005) Sparse, environmentally selective expression of Arc RNA in the upper blade of the rodent fascia dentata by brief spatial experience. Hippocampus 15:579-586. CrossRef Medline

Dantzer R, O'Connor JC, Freund GG, Johnson RW, Kelley KW (2008) From inflammation to sickness and depression: when the immune system subjugates the brain. Nat Rev Neurosci 9:46-56. CrossRef Medline

D’Arcangelo G, Tancredi V, Onofri F, D'Antuono M, Giovedì S, Benfenati F (2000) Interleukin-6 inhibits neurotransmitter release and the spread of excitation in the rat cerebral cortex. Eur J Neurosci 12:1241-1252. CrossRef Medline

Fanselow MS, Helmstetter FJ (1988) Conditional analgesia, defensive freezing, and benzodiazepines. Behav Neurosci 102:233-243. CrossRef Medline

Field RH, Gossen A, Cunningham C (2012) Prior pathology in the basal forebrain cholinergic system predisposes to inflammation-induced working memory deficits: reconciling inflammatory and cholinergic hypotheses of delirium. J Neurosci 32:6288-6294. CrossRef Medline

Frankland PW, Cestari V, Filipkowski RK, McDonald RJ, Silva AJ (1998) The dorsal hippocampus is essential for context discrimination but not for contextual conditioning. Behav Neurosci 112:863-874. CrossRef Medline

Gibertini M, Newton C, Friedman H, Klein TW (1995) Spatial learning impairment in mice infected with Legionella pneumophila or administered exogenous interleukin-1- $\beta$. Brain Behav Immun 9:113-128. CrossRef Medline

Griffin ÉW, Skelly DT, Murray CL, Cunningham C (2013) Cyclooxygenase1-dependent prostaglandins mediate susceptibility to systemic inflammation-induced acute cognitive dysfunction. J Neurosci 33: 15248-15258. CrossRef Medline

Guerreiro RJ, Santana I, Brás JM, Santiago B, Paiva A, Oliveira C (2007) Peripheral inflammatory cytokines as biomarkers in Alzheimer's disease and mild cognitive impairment. Neurodegener Dis 4:406-412. CrossRef Medline

Guzowski JF, McNaughton BL, Barnes CA, Worley PF (1999) Environment-specific expression of the immediate-early gene Arc in hippocampal neuronal ensembles. Nat Neurosci 2:1120-1124. CrossRef Medline

Guzowski JF, Knierim JJ, Moser EI (2004) Ensemble dynamics of hippocampal regions CA3 and CA1. Neuron 44:581-584. CrossRef Medline

Hennigan A, Trotter C, Kelly AM (2007) Lipopolysaccharide impairs longterm potentiation and recognition memory and increases p75NTR expression in the rat dentate gyrus. Brain Res 1130:158-166. CrossRef Medline

Henry CJ, Huang Y, Wynne A, Hanke M, Himler J, Bailey MT, Sheridan JF, Godbout JP (2008) Minocycline attenuates lipopolysaccharide (LPS)induced neuroinflammation, sickness behavior, and anhedonia. J Neuroinflammation 5:15. CrossRef Medline

Huijbregts SC, Kalkers NF, de Sonneville LM, de Groot V, Reuling IE, Polman CH (2004) Differences in cognitive impairment of relapsing remitting, secondary, and primary progressive MS. Neurology 63:335-339. CrossRef Medline

Jung MW, McNaughton BL (1993) Spatial selectivity of unit activity in the hippocampal granular layer. Hippocampus 3:165-182. CrossRef Medline

Kranjac D, McLinden KA, Deodati LE, Papini MR, Chumley MJ, Boehm GW (2012) Peripheral bacterial endotoxin administration triggers both memory consolidation and reconsolidation deficits in mice. Brain Behav Immun 26:109-121. CrossRef Medline

Layé S, Parnet P, Goujon E, Dantzer R (1994) Peripheral administration of lipopolysaccharide induces the expression of cytokine transcripts in the brain and pituitary of mice. Mol Brain Res 27:157-162. CrossRef Medline

Lechan RM, Toni R, Clark BD, Cannon JG, Shaw AR, Dinarello CA, Reichlin $S$ (1990) Immunoreactive interleukin-1 $\beta$ localization in the rat forebrain. Brain Res 514:135-140. CrossRef Medline

Leutgeb JK, Leutgeb S, Moser MB, Moser EI (2007) Pattern separation in the dentate gyrus and CA3 of the hippocampus. Science 315:961-966. CrossRef Medline

Livak KJ, Schmittgen TD (2001) Analysis of relative gene expression data using real-time quantitative PCR and the 2- $\Delta \Delta$ CT method. Methods 25 : 402-408. CrossRef Medline

McHugh TJ, Jones MW, Quinn JJ, Balthasar N, Coppari R, Elmquist JK, Lowell BB, Fanselow MS, Wilson MA, Tonegawa S (2007) Dentate gyrus NMDA receptors mediate rapid pattern separation in the hippocampal network. Science 317:94-99. CrossRef Medline

McNaughton BL, Morris RGM (1987) Hippocampal synaptic enhancement and information storage within a distributed memory system. Trends Neurosci 10:408-415. CrossRef

Meyers CA, Albitar M, Estey E (2005) Cognitive impairment, fatigue, and cytokine levels in patients with acute myelogenous leukemia or myelodysplastic syndrome. Cancer 104:788-793. CrossRef Medline

Niibori Y, Yu TS, Epp JR, Akers KG, Josselyn SA, Frankland PW (2012) Suppression of adult neurogenesis impairs population coding of similar contexts in hippocampal CA3 region. Nat Commun 3:1253. CrossRef Medline

O'Connor JJ, Coogan AN (1999) Actions of the pro-inflammatory cytokine Il- $1 \beta$ on central synaptic transmission. Exp Physiol 84:601-614. CrossRef Medline

Oitzl MS, van Oers H, Schöbitz B, de Kloet ER (1993) Interleukin-1 $\beta$, but not interleukin-6, impairs spatial navigation learning. Brain Res 613:160 163. Medline

Parsons TC, Otto T (2008) Temporary inactivation of dorsal hippocampus attenuates explicitly nonspatial, unimodal, contextual fear conditioning. Neurobiol Learn Mem 90:261-268. CrossRef Medline

Pevzner A, Miyashita T, Schiffman AJ, Guzowski JF (2012) Temporal dynamics of Arc gene induction in hippocampus: relationship to context memory formation. Neurobiol Learn Mem 97:313-320. CrossRef Medline

Pugh CR, Kumagawa K, Fleshner M, Watkins LR, Maier SF, Rudy JW (1998) Selective effects of peripheral lipopolysaccharide administration on con- 
textual and auditory-cue fear conditioning. Brain Behav Immun 12:212229. CrossRef Medline

Ramirez-Amaya V, Marrone DF, Gage FH, Worley PF, Barnes CA (2006) Integration of new neurons into functional neural networks. J Neurosci 26:12237-12241. CrossRef Medline

Ramirez-Amaya V, Angulo-Perkins A, Chawla MK, Barnes CA, Rosi S (2013) Sustained transcription of the immediate early gene Arc in the dentate gyrus after spatial exploration. J Neurosci 33:1631-1639. CrossRef Medline

Rosi S, Ramirez-Amaya V, Vazdarjanova A, Esparza EE, Larkin PB, Fike JR, Wenk GL, Barnes CA (2009) Accuracy of hippocampal network activity is disrupted by neuroinflammation: rescue by memantine. Brain 132: 2464-2477. CrossRef Medline

Satvat E, Schmidt B, Argraves M, Marrone DF, Markus EJ (2011) Changes in task demands alter the pattern of zif268 expression in the dentate gyrus. J Neurosci 31:7163-7167. CrossRef Medline

Schöbitz B, Voorhuis DAM, De Kloet ER (1992) Localization of interleukin 6 mRNA and interleukin 6 receptor mRNA in rat brain. Neurosci Lett 136:189-192. CrossRef Medline

Shaw KN, Commins S, O'Mara SM (2001) Lipopolysaccharide causes deficits in spatial learning in the watermaze but not in BDNF expression in the rat dentate gyrus. Behav Brain Res 124:47-54. CrossRef Medline

Shaw KN, Commins S, O'Mara SM (2005) Cyclooxygenase inhibition attenuates endotoxin-induced spatial learning deficits, but not an endotoxin-induced blockade of long-term potentiation. Brain Res 1038: 231-237. CrossRef Medline

Skaggs WE, McNaughton BL, Wilson MA, Barnes CA (1996) Theta phase precession in hippocampal neuronal populations and the compression of temporal sequences. Hippocampus 6:149-172. CrossRef Medline

Sparkman NL, Johnson RW (2008) Neuroinflammation associated with aging sensitizes the brain to the effects of infection or stress. Neuroimmunomodulation 15:323-330. CrossRef Medline
Thomson LM, Sutherland RJ (2005) Systemic administration of lipopolysaccharide and interleukin-1beta have different effects on memory consolidation. Brain Res Bull 67:24-29. CrossRef Medline

Thornton AE, Raz N, Tucke KA (2002) Memory in multiple sclerosis: contextual encoding deficits. J Int Neuropsychol Soc 8:395-409. CrossRef Medline

Vazdarjanova A, Guzowski JF (2004) Differences in hippocampal neuronal population responses to modifications of an environmental context: evidence for distinct, yet complementary, functions of CA3 and CA1 ensembles. J Neurosci 24:6489-6496. CrossRef Medline

Vazdarjanova A, McNaughton BL, Barnes CA, Worley PF, Guzowski JF (2002) Experience-dependent coincident expression of the effector immediate-early genes arc and Homer 1a in hippocampal and neocortical neuronal networks. J Neurosci 22:10067-10071. Medline

Wilson IA, Gallagher M, Eichenbaum H, Tanila H (2006) Neurocognitive aging: prior memories hinder new hippocampal encoding. Trends Neurosci 29:662-670. CrossRef Medline

Woods SP, Carey CL, Moran LM, Dawson MS, Letendre SL, Grant I (2007) Frequency and predictors of self-reported prospective memory complaints in individuals infected with HIV. Arch Clin Neuropsychol 22:187195. CrossRef Medline

Yaffe K, Lindquist K, Penninx BW, Simonsick EM, Pahor M, Kritchevsky S, Launer L, Kuller L, Rubin S, Harris T (2003) Inflammatory markers and cognition in well-functioning African-American and white elders. Neurology 61:76-80. CrossRef Medline

Yassa MA, Mattfeld AT, Stark SM, Stark CE (2011) Age-related memory deficits linked to circuit-specific disruptions in the hippocampus. Proc Natl Acad Sci U S A 108:8873-8878. CrossRef Medline

Yirmiya R, Goshen I (2011) Immune modulation of learning, memory, neural plasticity and neurogenesis. Brain Behav Immun 25:181-213. CrossRef Medline 